\title{
Practice of menstrual hygiene and associated factors among female Mehalmeda high school students in Amhara regional state, Ethiopia
}

\section{Teklemariam Ketema Gultie}

Department of Midwifery, College of Medicine \& Health Science, Arba Minch University, Arba Minch, Ethiopia

\section{Email address:}

tekledb2002@gmail.com

\section{To cite this article:}

Teklemariam Ketema Gultie. Practice of Menstrual Hygiene and Associated Factors among Female Mehalmeda High School Students in Amhara Regional State, Ethiopia. Science Journal of Public Health. Vol. 2, No. 3, 2014, pp. 189-195.

doi: 10.11648/j.sjph.20140203.18

\begin{abstract}
Introduction: Menstrual hygiene management has not received adequate attention in the reproductive health sectors in developing countries. In Africa the practice of menstrual hygiene management is still poor and the issue is under estimated. Due to poor menstrual hygiene management the adolescent girls are exposed for reproductive tract infection, school absenteeism and increase school dropout rate. Objectives: To assess the practice of menstrual hygiene and associated factors among female Mehalmeda high school students in Amhara regional state, Ethiopia. Methods: Institution based cross sectional study design conducted from April 01 to 30/2013 using multistage sampling technique. Four hundred ninety two study participants were selected and structured pretested questionnaire was used to collect information from the participants. The data was analyzed using SPSS version 16 Crude odds ratio (COR) and Adjusted odds ratio (AOR) was used to identify the association with $\mathrm{p}$ value $<0.05$ as significant. Result: Majority of the participants $(90.9 \%)$ practiced good menstrual hygiene and had high level of menstrual hygiene knowledge. After bivariate analysis, the significant factors of menstrual hygiene were entered in to the multivariate model. It revealed that good menstrual hygiene was practiced among those participants who had high level of knowledge about menstrual hygiene (OR 5.78: 95\% CI, 2.15-15.51), teachers as source of information (OR 7.64: 95\% CI, 2.16-27.03) and access for water (OR 6.5: 95\% CI, 2.08-20.32) and urban place of residence (OR 2.38: 95\% CI, 1.137, 3.05). Conclusion: Majority of the participants had high level of menstrual hygiene knowledge practiced good menstrual hygiene. Different factors affect the practice of menstrual hygiene such as source of information, access of water and knowledge about menstrual hygiene.
\end{abstract}

Keywords: Practice, Menstrual Hygiene, Mehalmeda, Cross-Sectional Study

\section{Introduction}

Menstruation is part of the female reproductive cycle that starts when girls become sexually mature at the time of puberty. It is essential that females are able to manage menstrual bleeding hygienically. However, menstrual hygiene management is insufficiently acknowledged and has not received adequate attention in the reproductive health sectors in developing countries and its impact on achieving several Millennium Development Goals [1]. Globally, half of the female population is of reproductive age [2] and at any given time, $25 \%$ of the female population is menstruating [3]. Menstruation is a natural process in a women's life and needs special care from a physical and psychological point of view [4]. In order for women and girls to live healthy, productive and dignified lives, it is essential that they are able to manage menstrual bleeding hygienically $[5,6]$.

In Bangladesh, a study showed that $95 \%$ of women and $90 \%$ of adolescent girls use rags during menstruation to absorb the flow of menstrual blood. The same study showed that $40 \%$ of women change their rags only once a day, $60 \%$ of women wash the rags in unsafe water and $80 \%$ of adolescent girls' reuse the rag [7]. In a study in Thiruvananthapuram city of south India, $45.5 \%$ reported using sanitary pads alone as menstrual absorbent, $38.2 \%$ use both cloth and sanitary pads and $16.3 \%$ cloth alone; $74.8 \%$ of adolescents changed sanitary towels/cloth 2-3 times a day [8].

United nations children's fund (UNICEF) estimates that about 1 in 10 school age African girls do not attend school during menstruation, or drop out at puberty because of the lack of clean and private sanitation facilities to manage their 
menstruation hygienically [9].

In Egypt Because of cultural and religious beliefs, menstruation is not considered an appropriate topic of discussion, leading to the lack of accurate information for girls to manage menstruation hygienically. In poor areas of Egypt, there is a problem of overcrowding and poor infrastructure both in schools and homes. Toilets may be totally absent or few in number, with broken doors or defective water supply and sewerage [10]. Menstrual hygiene needs to be addressed holistically and in context as a package of services that includes voice and space to talk about the issue, adequate water, privacy, facilities for washing and disposal of used sanitary pads [11].

The accessibility of private place to change their sanitary cloths or pads, clean water for washing hands and used cloths, and facilities for safely disposing of used materials affects the practice of menstrual hygiene [12]. Different studies indicate that good menstrual hygiene was practiced among those girls whose mothers were literate, girls studying in more than grade 10 in school, older girls, having prior knowledge about menstruation before menarche, presence of proper sanitary latrine at home, exposure to advertisements regarding usage of sanitary napkins in mass media, residential address and socioeconomic status of the family [13-16]. In Egypt the significant predictors of use of sanitary pads were availability of mass media at home, high and middle social class and urban residence [10].

In Ethiopia, like in many parts of the developing world, menstrual hygiene management is one of the critical challenges adolescent girls face while they are in school. This is largely due to lack of facilities as well as poor management of the existing facilities which is important for the management of menstrual hygiene [17]. A study conducted in 4 districts of Southern Ethiopia showed that the school environment was not conducive especially for menstrual hygiene management. This study revealed that $90 \%$ of the schools lack water supply, separate toilet for boys and girls and the existing toilets lack privacy. Girls used unhygienic rags during menstrual period and had little knowledge on how to keep personal hygiene during menstruation. The study indicated that menstruation is seen as a taboo by communities and school teachers. In addition, parents do not provide information and guidance on menstrual hygiene management which leaves school girls without assistance on how to manage their menstruation hygienically [18]. It is important to identify the practice of menstrual hygiene and associated factors among school going students to intervene accordingly. However, there is little known \& scarce study about menstrual hygiene and its associated factors among female students. So this study assessed the practice of menstrual hygiene and associated factors among female Mehalmeda high school students in Amhara regional state, Ethiopia.

\section{Methods and Participants}

An institution based cross sectional study was conducted from April 01 to 30/2013 on 492 female high school study participants. Mehalmeda high school is found in North shoa zone, Amhara regional state, Ethiopia. The school enrolled 3100 students in 2012/13 academic calendar and out these 1665 were female students. The school is located $200 \mathrm{~km}$ away from Addis Ababa; the capital city of Ethiopia.

Source population; the source population of this study were all female Mehalmeda high school students

Study population; the study population were female students in Mehalmeda high school during 2012/13 academic year at the time of study period.

Inclusion criteria; Female students enrolled in Mehalmeda high school in 2012/13 regular program, with no visual impairments and volunteer to participate in the study.

Exclusion criteria; students who are seriously ill at the time of data collection, evening class students and visually impaired students were excluded.

\subsection{Sample Size Determination and Sampling Techniques}

The sample size was determined by using single population proportion formula by considering the proportion of students who practiced good menstrual hygiene 50\% since there were no other studies done in the country. The calculated sample size was 384 . Since the source population is less than 10,000 finite population correction formulas was used. The calculated sample size was based on the assumption of simple random sampling (SRS) method. However, multi-stage sampling method were used, so as to achieve the same precision as simple random sampling the calculated sample size was multiplied by design effects of 1.5 and considering non response rate of $5 \%$, the total sample size taken was: $312 * 1.5=468$, the total sample size was $468+$ non response $5 \%(24)=492$. The data was collected by self-administered technique, using a questionnaire adapted from relevant literatures of similar studies. It consists of basic socio demographic characteristics, source of information about menstrual hygiene and information concerning the knowledge and practice of menstrual hygiene.

\subsection{Data Analysis Procedures}

The collected data was edited, coded and entered to a computer and analyzed by SPSS version 16. Missing values, outliers and normality of data were checked by data exploration. Proportion and bivariate analysis were carried out. Variables that were statically significant at bivariate level were used as candidate for multivariate analyses. Multiple logistic regressions used to analyze study variables.

\subsection{Operational Definitions}

Knowledge of menstrual hygiene: To measure the respondent's knowledge of menstrual hygiene there are 8 questions with each correct answer attracting 1 point and 0 for incorrect or don't know. Respondents that scored 50\% and above were considered as having high level knowledge while a score of less than $50 \%$ as low level of knowledge as 
similarly described by previous study [19].

Menstrual Hygiene practice: The measurement of practice of menstrual hygiene focus on use of material during menstruation (assign 1 point for use of sanitary pad, 0 other sanitary materials), methods of disposal of materials ( 0 for open field, 1 for other proper disposal), cleaning of external genitalia ( 1 for cleaning 2 or more times/day, 0 for $<2$ times/day), frequency of sanitary pad change (1 for changing pad 2 or more times/day, 0 for $<2$ times/day) and materials used for cleaning purpose (1 for washing with soap and water or with plain water, and 0 for not washing). Respondents who scored 5-9 points were adjudge as having good practice and respondents who scored 0-4 points were adjudged as having poor practices as similarly described in previous study [19].

\subsection{Ethical Consideration}

After thoroughly reviewed, ethical approval was obtained from Addis Ababa University College of health science institutional review board. The letter of cooperation was written from Department of Nursing and Midwifery to Mehalmeda high school. Schools' director was briefed on the objectives of the study. Each study participant was adequately informed about the purpose, anticipated benefit and risk of the study and their right to discontinue or refuse to participate in the study. Informed written consent was obtained from each study participants and their confidentiality, privacy and anonymity was maintained.

\section{Results}

\subsection{Distribution of Respondents by Socio-Demographic Characteristics}

Four hundred ninety two female students were participated in the study and response rate was $100 \%$. The mean age of the study participants was $16.85 \pm 1.336$ years. Among the participants $369(75 \%)$ of them were in the age group of 16-18 years and 315 (64\%) were grade 9. Among the respondents, 483(98.2\%) were orthodox Christian and 490(99.6\%) from Amhara Ethnic group. The majority of the respondents, $476(96.7 \%)$ were single and $285(57.9 \%)$ urban dwellers (table 1).

Table 1. Socio-demographic characteristic of female high school students in Mehalmeda, Amhara regional state, Ethiopia, 2013

\begin{tabular}{llll}
\hline Variables & Characterized & Frequency & Percentage \\
\hline \multirow{3}{*}{ Age of the } & 13-15 years & 85 & 17.3 \\
respondents & 16-18 years & 369 & 75.0 \\
& 19-21 years & 36 & 7.3 \\
& $>21$ years & 2 & 0.4 \\
Education level & grade 9 & 315 & 64.0 \\
& grade 10 & 123 & 25.0 \\
& grade 11 & 40 & 8.1 \\
Place of residence & grade 12 & 14 & 2.8 \\
& Urban & 285 & 57.9 \\
& Rural & 207 & 42.1 \\
\hline
\end{tabular}

\begin{tabular}{llll}
\hline Variables & Characterized & Frequency & Percentage \\
\hline \multirow{2}{*}{ Marital status } & Single & 476 & 96.7 \\
Fathers educational & Married & 16 & 3.3 \\
status & Illiterate & 71 & 14.4 \\
Mothers & Literate & 421 & 85.4 \\
educational status & Illiterate & 142 & 28.9 \\
& Literate & 350 & 71.1 \\
Parents occupation & Non-working & 19 & 3.9 \\
& Farmer & 349 & 70.9 \\
& Trade/business & 71 & 14.4 \\
& Employed & 53 & 10.8 \\
Family monthly & $<500$ birr & 241 & 49.0 \\
income & $500-1000$ birr & 133 & 27.0 \\
& $1000-1500$ birr & 62 & 12.6 \\
\hline
\end{tabular}

\subsection{Source of Information about Menstrual Hygiene}

The main source of information about menstrual hygiene was teacher for $212(43.1 \%)$ followed by mother for $113(22.96 \%)$. One hundred twenty seven $(25.8 \%)$ didn't learn about menstrual hygiene in the class and 167(33.9\%) didn't speak about menstrual hygiene with any one (table 2).

\subsection{Knowledge about Menstrual Hygiene}

The main materials known by 242(49.18\%) respondents were commercially made sanitary pad followed by 186 (37.8\%) underwear and 88(17.88\%) homemade pad. Three hundred fifty two $(71.5 \%)$ participant respond that there is foul odor during menstruation and $337(68.5 \%$ ) respond that menstrual blood is unhygienic. Four hundred nineteen $(85.2 \%)$ participants aware that poor menstrual hygiene predisposes for infection, 446(90.7\%) participants aware that sanitary pad should be changed frequently and $431(87.6 \%)$ respond that genitalia should be washed frequently. Three hundred seventy six $(76.4 \%)$ participants respond that personal hygiene has a role in prevention of menstrual pain. Four hundred forty six (90.7\%) study participant had high level of knowledge about menstrual hygiene and $46(9.3 \%)$ respondents had low level of menstrual hygiene knowledge (table 3 ).

\subsection{Menstrual Hygiene Practice of Respondents}

All respondents use menstrual absorbent; 349(70.9\%) use commercially made sanitary pad, $128(26.01 \%)$ homemade sanitary pad and $17(3.4 \%)$ use other methods such as underwear and sponge. One hundred forty six (29.7\%) of the participants reuse sanitary pad and 311(63.2\%) store sanitary pad in the bath room in between use. One hundred seventy one $(34.8 \%)$ participants changed pad two times per day and 94(19.1\%) changed only once per day. Two hundred fifty three $(51.4 \%)$ throw used menstrual soaking materials in the toilet pan and 45(9.1\%) throw used pad in the open field. One hundred eighty four $(37.4 \%)$ participants washed their genitalia twice per day and $6(1.2 \%)$ haven't washed during menstruation. Majority of them, 299(60.8\%) washed their genitalia with soap and water and the rest $187(30.8 \%)$ 
washed with water only. Only $76.8 \%$ respondents take bath or shower during menstruation and the rest of them didn't take bath or shower. Forty five $(9.1 \%)$ of the respondents practiced poor menstrual hygiene whereas 447(90.9\%) practiced good menstrual hygiene (table 4).

Table 2. Source of information about menstrual hygiene among female high school students in Mehalmeda Amhara regional state, Ethiopia, 2013

\begin{tabular}{llll}
\hline Variables & & Frequency & Percent \\
\hline Class about menstrual & Yes & 365 & 74.2 \\
hygiene & No & 127 & 25.8 \\
Speak about menstrual & Yes & 325 & 66.1 \\
hygiene & No & 167 & 33.9 \\
& Friend & 189 & 38.4 \\
With whom discuss about & Mother & 43 & 8.7 \\
menstrual hygiene* & Sister & 70 & 14.2 \\
& Teacher & 38 & 7.7 \\
& Teacher & 212 & 43.1 \\
Source of information about & Mother & 113 & 22.96 \\
menstrual hygiene* & Friend & 73 & 14.8 \\
& Media & 58 & 11.58 \\
\hline
\end{tabular}

* Refers some respondents have multiple responses

Table 3. Knowledge of menstrual hygiene among female high school students in Mehalmeda Amhara regional state, Ethiopia, 2013

\begin{tabular}{|c|c|c|c|}
\hline Variables & & Frequency & Percentage \\
\hline \multirow{3}{*}{$\begin{array}{l}\text { materials } \\
\text { known for } \\
\text { menstrual } \\
\text { soaking* }\end{array}$} & $\begin{array}{l}\text { Homemade pad or } \\
\text { cloth }\end{array}$ & 88 & 17.88 \\
\hline & $\begin{array}{l}\text { Commercially made } \\
\text { sanitary pad }\end{array}$ & 242 & 49.18 \\
\hline & Underwear & 186 & 37.8 \\
\hline \multirow{2}{*}{$\begin{array}{l}\text { Ideal type of } \\
\text { menstrual } \\
\text { absorbent }\end{array}$} & $\begin{array}{l}\text { Commercially made } \\
\text { sanitary pad }\end{array}$ & 429 & 87.2 \\
\hline & $\begin{array}{l}\text { Home made with } \\
\text { cloth piece }\end{array}$ & 63 & 12.8 \\
\hline Foul odor & No & 140 & 28.5 \\
\hline $\begin{array}{l}\text { during } \\
\text { menstruation }\end{array}$ & Yes & 352 & 71.5 \\
\hline Menstrual & No & 155 & 31.5 \\
\hline $\begin{array}{l}\text { blood } \\
\text { unhygienic }\end{array}$ & Yes & 337 & 68.5 \\
\hline $\begin{array}{l}\text { Poor menstrual } \\
\text { hygiene }\end{array}$ & No & 73 & 14.8 \\
\hline $\begin{array}{l}\text { predispose to } \\
\text { infection }\end{array}$ & Yes & 419 & 85.2 \\
\hline Pad should be & No & 46 & 9.3 \\
\hline $\begin{array}{l}\text { changed } \\
\text { frequently }\end{array}$ & Yes & 446 & 90.7 \\
\hline $\begin{array}{l}\text { Genitalia } \\
\text { should be }\end{array}$ & No & 61 & 12.4 \\
\hline $\begin{array}{l}\text { washed } \\
\text { frequently }\end{array}$ & Yes & 431 & 87.6 \\
\hline $\begin{array}{l}\text { Personal } \\
\text { hygiene }\end{array}$ & No & 116 & 23.6 \\
\hline $\begin{array}{l}\text { prevent } \\
\text { menstrual pain }\end{array}$ & Yes & 376 & 76.4 \\
\hline $\begin{array}{l}\text { Knowledge } \\
\text { about }\end{array}$ & High level knowledge & 446 & 90.7 \\
\hline $\begin{array}{l}\text { menstrual } \\
\text { hygiene }\end{array}$ & Low level knowledge & 46 & 9.3 \\
\hline
\end{tabular}

* Refers some respondents have multiple responses

\subsection{Factors Affecting the Practice of Menstrual Hygiene}

It was tried to assess the factors that are affecting the practice of menstrual hygiene. Different socio demographic and menstruation related variables were entered in binary logistic regression. After bivariate analysis, the significant predictors of good menstrual hygiene were entered in to the multivariate model. It revealed that the practice of good menstrual hygiene was more among students who live in the urban (AOR 2.38: 95\% CI, 1.137, 3.05) than those students who live in the rural area, whose source of information was teacher (AOR 7.645: 95\% CI, 2.162, 27.032) than students whose source of information was mother, who have access for water (AOR 6.504: 95\% CI, 2.082, 20.323) were more practiced good menstrual hygiene than those who didn't have access for water, who had high level of Knowledge about menstrual hygiene (AOR 5.783: 95\% CI, 2.156, 15.511) than those students who had low level of menstrual hygiene knowledge (table 5).

Table 4. Practice of menstrual hygiene among female Mehalmeda high school students in Amhara regional state, Ethiopia, 2013

\begin{tabular}{|c|c|c|c|}
\hline Variables & & Frequency & Percentage \\
\hline \multirow{2}{*}{$\begin{array}{l}\text { Use of sanitary } \\
\text { pad }\end{array}$} & No & 0 & 0 \\
\hline & Yes & 492 & 100 \\
\hline \multirow{4}{*}{$\begin{array}{l}\text { Materials used } \\
\text { for menstrual } \\
\text { absorbent* }\end{array}$} & Homemade cloth & 128 & 26.01 \\
\hline & Commercially made & 349 & 70.9 \\
\hline & Underwear & 15 & 3.0 \\
\hline & Sponge & 2 & 0.4 \\
\hline \multirow{2}{*}{$\begin{array}{l}\text { Reuse of } \\
\text { sanitary pad }\end{array}$} & No & 346 & 70.3 \\
\hline & Yes & 146 & 29.7 \\
\hline \multirow{3}{*}{$\begin{array}{l}\text { Place of pad } \\
\text { store in } \\
\text { between use }\end{array}$} & In the bath room & 311 & 63.2 \\
\hline & With other cloth & 75 & 15.2 \\
\hline & Separately & 106 & 21.5 \\
\hline \multirow{4}{*}{$\begin{array}{l}\text { Frequency of } \\
\text { changing pad } \\
\text { per day }\end{array}$} & Once & 94 & 19.1 \\
\hline & Two times & 171 & 34.8 \\
\hline & Three times & 164 & 33.3 \\
\hline & Four and above times & 63 & 12.8 \\
\hline \multirow{6}{*}{$\begin{array}{l}\text { Place where } \\
\text { dispose used } \\
\text { pad }\end{array}$} & Burry & 114 & 23.2 \\
\hline & Burn & 58 & 11.8 \\
\hline & With other waste & 18 & 3.7 \\
\hline & In the toilet pan & 253 & 51.4 \\
\hline & In the open field & 45 & 9.1 \\
\hline & In the latrine & 4 & 0.8 \\
\hline \multirow{5}{*}{$\begin{array}{l}\text { Frequency of } \\
\text { washing } \\
\text { genitalia per } \\
\text { day }\end{array}$} & Once & 91 & 18.5 \\
\hline & Two times & 184 & 37.4 \\
\hline & Three times & 155 & 31.5 \\
\hline & Four and above times & 56 & 11.4 \\
\hline & $\begin{array}{l}\text { No wash during } \\
\text { menstruation }\end{array}$ & 6 & 1.2 \\
\hline \multirow{2}{*}{$\begin{array}{l}\text { Materials used } \\
\text { for washing } \\
\text { genitalia }\end{array}$} & With soap and water & 299 & 60.8 \\
\hline & With water only & 187 & 30.8 \\
\hline \multirow{2}{*}{$\begin{array}{l}\text { Bath during } \\
\text { your period }\end{array}$} & No & 114 & 23.2 \\
\hline & Yes & 378 & 76.8 \\
\hline \multirow{2}{*}{$\begin{array}{l}\text { Practice of } \\
\text { menstrual } \\
\text { hygiene }\end{array}$} & Good practice & 447 & 90.9 \\
\hline & Poor practice & 45 & 9.1 \\
\hline
\end{tabular}

*refers some respondents have multiple response 
Table 5. Multiple logistic regression analysis for Factors affecting the practice of menstrual hygiene among female Mehalmeda high school students in Amhara regional state, Ethiopia, 2013

\begin{tabular}{|c|c|c|c|c|c|}
\hline \multirow{2}{*}{\multicolumn{2}{|c|}{ Respondents characteristics }} & \multicolumn{2}{|c|}{ Menstrual hygiene practice } & \multirow{2}{*}{$\operatorname{COR}(95 \%$ C.I $)$} & \multirow{2}{*}{$\operatorname{AOR}(95 \%$ C.I) } \\
\hline & & Good $(\%)$ & Poor (\%) & & \\
\hline \multirow{2}{*}{ Place of residence } & Urban & $268(94 \%)$ & $17(6 \%)$ & $2.466(1.311,4.638)$ & $2.38(1.137,3.05)^{* *}$ \\
\hline & Rural & $179(86.5 \%)$ & $28(13.5 \%)$ & 1 & 1 \\
\hline \multirow{4}{*}{ Source of information } & Mother & $97(90.7 \%)$ & $10(9.3 \%)$ & 1 & 1 \\
\hline & Teacher & $196(92.5 \%)$ & $16(7.5 \%)$ & $1.262(1.85,19.191)$ & $7.645(2.162,27.032)^{* *}$ \\
\hline & Friends & $58(86.6 \%)$ & $9(13.4 \%)$ & $0.664(0.471,4.287)$ & $1.5(0.441,5.101)$ \\
\hline & Media & $50(96.2 \%)$ & $2(3.8 \%)$ & $2.577(0.611,13.428)$ & $3.497(0.644,18.993)$ \\
\hline \multirow{2}{*}{ Access for Water } & Present & $420(91.9 \%)$ & $37(8.1 \%)$ & $1.363(1.427,7.929)$ & $6.504(2.082,20.323)^{* * *}$ \\
\hline & Absent & $27(77.1 \%)$ & $8(22.9 \%)$ & 1 & 1 \\
\hline \multirow{2}{*}{$\begin{array}{l}\text { Knowledge of menstrual } \\
\text { hygiene }\end{array}$} & High & $420(94.2 \%)$ & $26(5.8 \%)$ & $11.3628(5.6,23.077)$ & $5.783(2.156,15.511)^{* * *}$ \\
\hline & Low & $27(58.7 \%)$ & $19(41.3 \%)$ & 1 & 1 \\
\hline
\end{tabular}

$* *=$-value $<0.01, * * *=$-value $<0.001$

\section{Discussion}

In this study, 446(90.7\%) had high level of knowledge about menstrual hygiene. This finding is similar with the study done in northwest Nigeria which indicated that $91.5 \%$ of the participants had high level of knowledge (19).The finding is also higher than the result of the study done in Nepal which showed that only $40.6 \%$ had good knowledge about menstrual hygiene (3). This difference might be due to the reason that mothers in Nepal were not interested to express their views and to educate their daughters about menstrual hygiene because of the taboo of discussing about menstruation.

It was observed that in this study $90.9 \%$ had good practice of menstrual hygiene. This is similar with the study done in north western Nigeria which showed that $88.7 \%$ had good practice of menstrual hygiene [19]. This finding is higher than the study done in Gujjar which indicated that only 3.1\% practices good menstrual hygiene [20]. This difference might be due to illiteracy of the Gujjar girls which affects their hygienic practices. Lower level of practice was recorded from similar studies in Nepal which indicated that only $12.9 \%$ of the study participants practice good menstrual hygiene [3]. This deference could be related to poor Knowledge of Nepal's girls about menstrual hygiene which affects their level of practice.

There was significant association between level of knowledge and practice of menstrual hygiene. Those participants who had high level of knowledge were practice good menstrual hygiene than those students who had low level of menstrual hygiene knowledge. This finding is similar with the study done in urban slum of Mumbai and Kano Northwestern Nigeria [19, 21]. This study finding is different from the study done in Bangalore, India which showed that there was no association between knowledge and practice [22]. This difference could be due to the cultural restriction of washing or bathing in the Bangalore which affects their level of menstrual hygiene practices regardless of the level of knowledge.

Source of information about menstrual hygiene was significantly associated with the practice of menstrual hygiene $(\mathrm{p}=0.002)$. Those students who had information from their teacher were practicing good menstrual hygiene compared to the students who received information from their mothers. In contrast to this finding study in Sokoto, Nigeria showed that there was no significant association $(p=0.304)$ between the source of information and the level of menstrual hygiene practice [13].

Place of residence was found to be significantly associated with the practice of menstrual hygiene. It was observed that girls who live in the urban had good practice $(\mathrm{AOR}=2.466)$ of menstrual hygiene than those living in the rural area. This result is consistent with the finding in Bangalore India [22], as well as in Egypt (AOR=2.98) [10].

The study done in West Bengal showed that students whose mother was literate were practicing good menstrual hygiene than those students with illiterate mothers (14). This result is different from the current study which didn't show significant relation between maternal education and practice of menstrual hygiene. This difference could be due to the similar genital hygiene practice in the present study area.

There was significant association observed between the accessibility of water and practice of menstrual hygiene (AOR=6.504). Those participants who had access for water were practiced good menstrual hygiene. This finding is similar with the study done in India which indicated that access for water was strong predictor of good practice of menstrual hygiene [23].

\section{Conclusion}

The majority of the participants had high level of menstrual hygiene knowledge. The practice of menstrual hygiene was high among the study participants and different factors affect the level of practice such as access of water, knowledge about menstrual hygiene and source of information. Knowledge about menstrual hygiene was the most influencing factors for the practice of menstrual hygiene. Those students who had high level of knowledge were practiced good menstrual hygiene than those participants who had low level of menstrual hygiene knowledge. 


\section{Recommendation}

- The government should give special emphasis on making the accessibility of water and toilet facility in the school which decreases school absenteeism of female students due to menstrual hygiene problem.

- It is very important that the mother should have the correct and appropriate information on menstrual hygiene to give her knowledge to her girl child.

- It is essential for the teachers to incorporate reproductive health education, including menstrual hygiene to their students in the school curriculum to improve their knowledge and practice.

- Health professionals should educate the community about menstruation to avoid restrictions during menstruation and to educate the girl child about good management of menstrual hygiene

- Researchers has to do large scale study on menstrual hygiene by employing both qualitative and quantitative methods

\section{Limitation}

This study utilized cross sectional design which made the finding impossible to establish causal relationship between the outcome and exposure variables. Due to the sensitive nature of the issue there may social desirability bias.

\section{Acknowledgements}

My earnest gratitude goes to the Mehalmeda high school teachers, data collectors and the study participants for their cooperation and assistance and Addis Ababa University for funding the study.

\section{References}

[1] Water Aid. Menstrual hygiene and management an issue for adolescent school girls. 2009 [cited 2012 15/12]; Available from: www.wateraid.org/nepal.

[2] Population Reference Bureau. The world's women and girls' data sheet. 2011 [cited 2012 15/12]; Available from: www.prb.org/

pdf11/world-women-girls-2011-data-sheet.pdf.

[3] Adhikari P. Knowledge and practice regarding menstrual hygiene in rural adolescent girls of Nepal. Kathmandu University Medical Journal .2007; 5(19): 382-386.

[4] Menstrual cycle. 2006 [cited 2012 15/11]; Available from http://en.wikipedia.org/wiki/Menstrualcycle

[5] Mahon T, Fernandes M. Menstrual hygiene in South Asia: a neglected issue for WASH (water, sanitation and hygiene) programs. Gend Dev. 2010; 18(1):99-113.

[6] Abera Y. "Menarche, menstruation related problems and practices among adolescent high school girls in Addis Ababa" unpublished.
[7] Ahmed R, Yesmin K. menstrual hygiene: breaking the silence. $2011 \quad$ [cited 2012 13/12]. Available from http://www.wsscc.org/sites/default/files/publications/ahmedhygiene_promotion_breakingthesilence_bangaldesh-2008.p df

[8] Renjit M. Menstrual disorders and menstrual hygiene practices in higher Secondary School girls. Indian J Pediatr. 2012; 79(1):S74-S78

[9] UNICEF. Sanitation, the challenge. 2005 [cited 2012 Nov 20]; available at: http://www.childinfo.org/areas/sanitation/

[10] El-Gilany A, Badawi K, El-Fedawy S. Menstrual hygiene among adolescent schoolgirls in Mansoura, Egypt. Reproductive Health Matters. 2005; 13: 147-152.

[11] Tjon V. Menstrual hygiene a neglected Condition for the achievement of several millennium development Goals. 2007 [cited 2012 15/11]; Available at: http://www.eepa.be/wcm/ dmdocuments/Bgpaper_Menstrual Hygiene.pdf.

[12] House S, Mahon T, Cavill S. Menstrual hygiene the basics. 2012 [cited 2012 15/11]; Available from: www.wateraid.org/mhm

[13] Subhash B, Sushama S, Monica R, Nidhi R, Ketaki P, Suresh U. Menstrual hygiene knowledge and practice among adolescent school girls of Saoner, Nagpur district. Journal of Clinical and Diagnostic Research. 2011; 5(5): 1027-1033.

[14] Ray Sudeshna DA. Determinants of Menstrual Hygiene among Adolescent Girls. National journal of community medicine. 2012; 3(2):294-301.

[15] Omidvar S, Begum K. Factor's influencing hygienic practice during menses among girls from south India. International Journal of Collaborative Research on Internal Medicine \& Public Health. 2010; 2(12):411-423.

[16] Sabina F. Providing sex education to adolescents in rural Bangladesh: Experiences from BRAC. Gender \& Development. 2000; 8(2): 28-37

[17] Tsegaye Z, Tamiru S, Kitaba A, Getachew F. Towards a local solution for menstrual hygiene management in school. 2011 [cited $2012 \quad 15 / 11] ; \quad$ Available from: www.snvworld.org/sites/www.snvworld.org/files/publicatio ns/towards a local solution to menstrual_hygiene in_sch ools.pdf

[18] Montgomery P, Ryus C, Dolan C, Dopson S, Scott L. Sanitary pad interventions for girls' education in Ghana: A Pilot Study. PloS ONE. 2012; 7(10):1-7.

[19] Lawan U, Yusuf N, Musa A. Menstruation and menstrual hygiene amongst adolescent school girls in Kano, Northwestern Nigeria. African Journal of Reproductive Health. 2010; 14(3):201-7.

[20] Dhingra R, Kumar A. "Knowledge and practices related to menstruation among tribal (Gujjar) adolescent girls". Etho-Med. 2009; 3 (1):43-48.

[21] Prateek S, Saurabh R. A cross sectional study of knowledge and practices about reproductive health among female adolescents in an Urban Slum of Mumbai. Journal of Family and Reproductive Health. 2011; 5(4):117-124. 
[22] Shanbhag D, Shilpa R, D'Souza N, Josephine P, Singh J, Goud B. Perceptions regarding menstruation and Practices during menstrual cycles among high school going adolescent girls in resource limited settings around Bangalore city, Karnataka, India. International Journal of Collaborative Research on Internal Medicine \& Public Health.2012;
4(7):1353-1362.

[23] Salve B, Dase K, Mahajan M, Adchitre A. Assessment of knowledge and practice about menstrual hygiene amongst rural and urban Adolescent girls. International Journal of Recent Trends in Science and Technology. 2012; 3(3):65-70.. 